\title{
Uzaktan Eğitimde Kullanılan Bulanık Mantık Tabanlı Öğrenme Modelleri, Platformlar, Ölçme ve Değerlendirme Yöntemleri
}

\author{
Beyza Esin Özseven ${ }^{1 *}$, Naim Çağman ${ }^{2}$ \\ 1* Tokat Gaziosmanpaşa Üniversitesi, Lisanüstü Eğitim Enstitüsü, Matematik Bölümü, Tokat, Türkiye, (ORCID: 0000-0003-4888-8259), beyza esin@hotmail.com \\ 2 Tokat Gaziosmanpaşa Üniversitesi, Fen-Edebiyat Fakültesi, Matematik Bölümü, Tokat, Türkiye (ORCID: 0000-0003-3037-1868), naim.cagman@gop.edu.tr
}

(İlk Geliş Tarihi 17 Mart 2021 ve Kabul Tarihi 26 Haziran 2021)

(DOI: 10.31590 /ejosat.898349)

ATIF/REFERENCE: Esin Özseven, B. \& Çağman, N. (2021). Uzaktan Eğitimde Kullanılan Bulanık Mantık Tabanlı Öğrenme Modelleri, Platformlar, Ölçme ve Değerlendirme Yöntemleri. Avrupa Bilim ve Teknoloji Dergisi, (25), 406-416.

\begin{abstract}
Öz
Uzaktan eğitim, geleneksel eğitimin teknolojik araçlar yardımıyla zaman ve mekan bağımsız olarak gerçekleştirilmesidir. Teknolojik gelişmeler ve pandemi sürecinin başlaması ile birlikte uzaktan eğitime olan talep çok yüksek seviyelere ulaşmıştır. Uzaktan eğitim sürecinin başarı ile idame ettirilmesi ve öğrencinin eğitim hayatını başarılı bir şekilde sürdürülmesi için kullanılacak öğrenme modelleri, platformlar ve ölçme değerlendirme yöntemleri önem arz etmektedir. Bu çalışma, uzaktan eğitimde kullanılan öğrenme modelleri, platformlar, ölçme ve değerlendirme ve uzaktan eğitimde bulanık mantığın kullanımına ilişkin bir derleme çalışmasıdır. Araştırma kapsamında uzaktan eğitimin uygulanmasına ilişkin literatür taraması yapılmıştır. Araştırma sonucunda, senkron ve asenkron sistemleri destekleyen platformların daha etkin eğitim sağladığı, öğrencilerin sistemi kullanım desenlerinin de ön planda olduğu, akademik güvensizliğin önüne geçmek için yapay zeka tekniklerinden yararlanıldığı ortaya konulmuştur. Ayrıca, bulanık mantığın öğrenme desenlerinin belirlenmesi, platform seçimi ve ölçme ve değerlendirme de yaygın olarak kullanıldığı sonucuna ulaşılmıştır.
\end{abstract}

Anahtar Kelimeler: Uzaktan Eğitim, Yapay Zeka, Bulanık Mantık, Ölçme ve Değerlendirme.

\section{Learning Models, Platforms, Measurement and Evaluation Methods Based on Fuzzy Logic Used in Distance Education}

\begin{abstract}
Distance education is the realization of traditional education independent of time and place with the help of technological tools. With the technological developments and the pandemic, the demand for distance education has reached very high levels. Learning models, platforms and assessment and evaluation methods to be used for the successful continuation of the distance education process and the successful education of the student are important. This study is a review study on learning models, platforms, measurement and evaluation used in distance education, and the use of fuzzy logic in distance education. Within the scope of the research, literature review on the application of distance education has been made. As a result of the research, it was revealed that platforms that support synchronous and asynchronous systems provide more effective training, students' system usage patterns are also at the forefront, and artificial intelligence techniques are used to prevent academic insecurity. In addition, it was concluded that fuzzy logic is widely used in determining learning patterns, platform selection, and assessment and evaluation.
\end{abstract}

Keywords: Distance Learning, Artificial Intelligance, Fuzzy Logic, Measurement and Evaluation.

\footnotetext{
*Sorumlu Yazar: beyza esin@hotmail.com
} 


\section{Giriş}

Uzaktan eğitim, hem eğitimci hem de öğrencinin zaman ve mekandan bağımsız olarak bir araya geldiği ve teknolojik imkanlarla eğitim sürecini devam ettirdiği eğitim sistemidir (Ulutaş \& Ubuz, 2008).

Dünya genelinde eğitim sistemleri, 2020'de yaşanan pandemiden sonra kendisini yenilemek zorunda kalmıştır. UNESCO verileri, 17 Nisan 2020 tarihinden sonra dünya genelinde okul öncesinden yükseköğretime dünya genelinde \%91,3'üne karşılık gelen 1.724.657.870 öğrenci salgından etkilendiğini göstermektedir. Uzaktan eğitimin daha aktif ve kovid-19 öncesinde daha az tercih edilen kitlesel çevrimiçi açık kurs (MOOC) eğitimlerinden daha fazla faydalanılacağ 1 muhtemeldir. 2020 uluslararası yükseköğretim forumu'nda, pandeminin dünya genelinde yükseköğretim sistemine, eğitimöğretim metodu, araştırma, uluslararasılaşma, hareketlilik konularında derin etkiler ve değişiklikler getireceği yönünde söylemler gerçekleşti ve bugün itibariyle, dijital eğitime artık yoğun bir akın başlamıştır (Saraç, 2020).

Günümüz uzaktan eğitim teknolojileri temel olarak senkron ve asenkron olarak 2 gruba ayrılabilir. Senkron eğitim, yüz yüze eğitime benzer yapıya sahip olmakla birlikte yüz yüze eğitimden farklı olarak öğrenci ve öğretmen aynı fiziksel ortamı paylaşmamaktadır. Eğitim canlı olarak gerçekleştirilse de öğrenci ile etkileşim düşük düzeydedir. Birçok eğitimci etkileşimi artırmak için ders esnasında öğrencilerin kamera ve ses sistemlerinin açık olmasını tercih etmektedir. Ancak, kullanılan alt yapının yetersizliği çoğunlukla buna müsaade etmemektedir. Bunun sonucu olarak da ders tam olarak etkileşimli gerçekleştirilememektedir. Asenkron eğitimde ise ders materyalleri dosya veya video kaydı şeklinde öğrencilerle paylaşılmaktadır. Öğrencinin takibi sadece materyallere erişimlerinin, video izleme ve sistemde kalma sürelerinin takibi ile gerçekleştirilmektedir. Ancak, birçok öğrenci sistemi belirli bir süre açık bırakarak devam zorunluluğunu tamamlamaktadır.

Uzaktan eğitimdeki temel problemleri ele alacak olursak; kullanılacak eğitim sisteminin tercihi, öğrenci devamının takibi ve öğrenci performansının değerlendirilmesi eğitsel açıdan ortaya çıkan temel problemlerdir. Bununla birlikte teknolojik altyapının yetersizliğini de teknik bir problem olarak değerlendirebiliriz.

Günümüzde birçok eğitim kurumu uzaktan eğitim altyapısına sahiptir. $\mathrm{Bu}$ altyap1 oluşturulurken Moodle (Moodle - Opensource learning platform | Moodle.org, t.y.) gibi aç1k kaynak kodlu web tabanlı yazılımlar, hazır portallar veya kurumların kendi geliştirdiği yazılımlar tercih edilmektedir. Ancak, bu yazılımlar asenkron eğitime olanak sağlamaktadır. Eğitimci bu yazılımlar üzerinden dosya paylaşımı, video paylaşımı vb. yapabilir. Ancak, senkron ders yapmak istediğinde Zoom (Zoom, t.y.), Microsoft Teams (Microsoft Teams, t.y.), Cisco Webex (Cisco Webex, t.y.), GoToMeeting (GoToMeeting, t.y.) veya açık kaynak kodlu eklentiler kullanılması gerekmektedir. Öğrenci başarısının değerlendirilmesi için ise uzaktan eğitim sistemine çevrimiçi sınav eklentileri dahil edilmektedir. Bu tür sınavlardaki temel problem öğrencinin kopya çekmesidir. Bunun önüne geçmek için sınav için özel süre tanımlaması veya soru havuzundan her öğrenci için farklı soru çekilmesi kullanılan bazı yöntemlerdir. Diğer bir yöntem ise her öğrencinin sınav süresince kameradan takip edilmesidir. Bir eğitim kurumu tüm olanaklara sahip olsa dahi bu kez karşılaşacağı en büyük sorun bu sistemi sorunsuz şekilde idame ettirebilecek teknolojik donanıma sahip olup olmadığıdır.

$\mathrm{Bu}$ çalışmada, uzaktan eğitimde kullanılan öğrenme modelleri, platformlar ve uzaktan eğitimde bulanık mantığın kullanımına yönelik çalışmalar incelenmiştir. Çalışmanın ikinci bölümünde uzaktan eğitim modelleri, üçüncü bölümünde uzaktan eğitim platformları, dördüncü bölümde uzaktan eğitimde ölçme ve değerlendirme sistemleri ve son bölümde bulanık mantığın uzaktan eğitimdeki uygulamaları verilmiştir.

\section{Uzaktan Eğitim Modelleri}

Uzaktan eğitim temel olarak tek yönlü ve çift yönlü olarak iki model üzerine yoğunlaşmıştır. Tek yönlü model teknolojik gelişmeler öncesi kullanılan ve katılımcılar arasındaki iletişimin tek yönlü olduğu eğitim modelidir. Dolayısıyla katılımcılar arasında eşzamanlı iletişim yoktur. İletişim, mektup, e-posta, radyo-TV gibi ortamlar üzerinden gerçekleşir. Öğrenciler dersi dinleme, izleme veya internet ortamı üzerinden öğrenir (İşman, 1998). Çift yönlü iletişimde ise katılımcılar çift yönlü ve eşzamanlı olarak iletişim kurabilir. Uzaktan eğitimde teknoloji kullanımına yönelik birçok uygulama modeli ortaya çıkmıştır.

Uzaktan eğitim modelleri günümüzde kullanım şekline göre değerlendirecek olursak senkron (eşzamanlı) ve asenkron (eş zamansız) olarak gruplandırılabilir.

Senkron eğitim, eğitimci ve öğrencinin sanal sınıf ortamında birlikte bulunduğu sistemlerdir. İletişim eğitimcinin kontrolünde karşılıklı olarak anlık gerçekleştirilebilir. Bu tür ortamların en önemli avantaj1, "öğrenci-öğrenci" ya da "eğitimci-öğrenci" arasındaki etkileşimi sağlayabilecek araçların kullanımına uygun olmaları nedeniyle, geleneksel sinif ortamına benzer ortam oluşturmaktadır (Can, 2008; Özkaraca, 2005). Yüksek geniş bant internet bağlantısına ihtiyaç vardır.

Asenkron eğitimde eğitimci ve öğrenci birbirinden bağımsız olarak sistemi istediği zaman kullanabilir. Eğitimci öğrenme materyallerini sisteme doküman, video veya sunu gibi formatlarda yükleyebilir. Öğrenci de eğitimcinin paylaşımlarına erişim sağlayabilir. Minimum altyapı ile sistem kullanılabilir.

Uzaktan eğitim ortamlarındaki en büyük sorun tüm kullanıcıların çok iyi bir teknik donanım, alt yapı ve teknolojiyi kullanabilme yetisine ihtiyaç olmasıdır.

\section{Uzaktan Eğitim Platformları}

Gerek ulusal gerekse de uluslararası bağlamda birçok eğitim kurumu uzaktan eğitimi uzun yıllardır kullanmaktadır. Ancak, pandemi dönemi ile eğitimin sürekliliği için uzaktan eğitime talep çok fazla artmıştır.

Literatürde MOOC ve canlı ders yazılımları incelendiğinde birçok çalışma mevcuttur (Herand \& Hatipoğlu, 2014; Işık vd., 2010; İzmirli \& Akyüz, 2017; Lavolette vd., 2010; Schullo vd., 2007; Yıldırım vd., 2011). Bu çalışmalar, Adobe Connect, Big Blue Button, Blackboard Collaborate, Electa Live, GoToTraning, Openmeetings, Perculus, VMukti ve WizIQ gibi birçok yazılımı karşılaştırmıştır. Teknoloji dünyasında kullanılan yazılımlar bunlarla sınırlı değildir. Bunlara ek olarak açık kaynak kodlu çeşitli yazılımlar ve kurumların kendileri geliştirdikleri platformlarda mevcuttur.

Kullanılacak yazılımın belirlenmesinde canlı ders süresi, katılımcı sınırı, kayıt özelliği gibi öncelikli gereksinimlerin göz 
önüne alınması gerekmektedir. Bu gereksinimlere ek olarak bütçe, teknik altyapı ve kullanım kolaylığı da göz önüne alınmalıdır.

Durak vd.'nin yaptığ 1 çalışmada Türkiye'deki üniversitelerde kullanılan uzaktan eğitim sistemleri ile ilgili araştırma yapmıştır (Durak vd., 2020). Yapılan araştırmanın bulgularına göre Moodle, ALMS, Microsoft Teams, Üniversite Bilgi Yönetim Sistemi (ÜBYS), Toltek, Google G-Suite, Sakai, Blackboard Learn, Canvas ve SIYDEM yönetim sistemleri kullanılmaktadır (kullanım yoğunluklarına göre sıralı verilmiştir). Bu sistemler öğrenme yönetim sistemi olarak kullanılmaktadır. Bu sistemler üzerinden öğrenci ve eğitimci aynı platformda bir araya getirilmekte ve kaynak paylaşımı sağlanmaktadır. Yani süreç asenkron olarak işlemektedir. Derslerin canlı olarak işlenmesi için

Tablo 1. Öğrenme yönetim sistemlerinin karşılaştırması (Aydoğdu Karaaslan, 2019; Herand \& Hatipoğlu, 2014; Karadimas, 2018; Küçükönder \& İbrahim, 2016).

\begin{tabular}{|c|c|c|c|c|c|c|c|c|c|}
\hline & $\begin{array}{l}\stackrel{0}{\sigma} \\
\stackrel{0}{g} \\
\dot{\theta}\end{array}$ & $\sum_{2}^{\infty}$ & 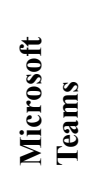 & 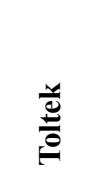 & 矛 & 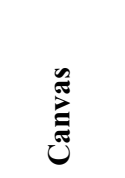 & $\sum_{0}$ & $\begin{array}{l}x \\
0 \\
0 \\
0 \\
0 \\
0\end{array}$ & 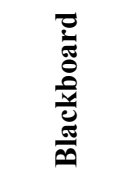 \\
\hline Lisans & Ücretsiz & Ücretli & Ücretli & Ücretli & Ücretsiz & Ücretsiz & Ücretli & Ücretsiz & Değişken \\
\hline Dosya Paylaşımı & $\checkmark$ & $\checkmark$ & $\checkmark$ & $\checkmark$ & $\checkmark$ & $\checkmark$ & $\checkmark$ & $\checkmark$ & $\checkmark$ \\
\hline Sohbet & $\checkmark$ & $\checkmark$ & $\checkmark$ & $\checkmark$ & $\checkmark$ & $\checkmark$ & $\checkmark$ & $\checkmark$ & $\checkmark$ \\
\hline Genişletilebilirlik & $\checkmark$ & $x$ & $x$ & $x$ & $x$ & $\checkmark$ & $x$ & $\checkmark$ & $x$ \\
\hline Raporlama & $\checkmark$ & $\checkmark$ & $\checkmark$ & $\checkmark$ & $\checkmark$ & $x$ & $\checkmark$ & $\checkmark$ & $\checkmark$ \\
\hline Web tabanlı & $\checkmark$ & $\checkmark$ & $\checkmark$ & $\checkmark$ & $\checkmark$ & $\checkmark$ & $\checkmark$ & $\checkmark$ & $\checkmark$ \\
\hline Masaüstü & $x$ & $x$ & $\checkmark$ & $x$ & $\checkmark$ & $x$ & $x$ & $x$ & $x$ \\
\hline Mobil & $x$ & $x$ & $\checkmark$ & $x$ & $x$ & $\checkmark$ & $x$ & $x$ & $x$ \\
\hline Sınav/Ödev & $\checkmark$ & $\checkmark$ & $\checkmark$ & $\checkmark$ & $x$ & $\checkmark$ & Eklenti & Eklenti & $\checkmark$ \\
\hline Ders Tanımlama ve Atama & $\checkmark$ & $\checkmark$ & $x$ & $\checkmark$ & $\checkmark$ & $\checkmark$ & $\checkmark$ & $\checkmark$ & $\checkmark$ \\
\hline E-mail entegrasyonu & $\checkmark$ & $\checkmark$ & $\checkmark$ & $\checkmark$ & $x$ & $\checkmark$ & $\checkmark$ & $\checkmark$ & $x$ \\
\hline Kullanıc1 Sinırı & Sinırs1z & Sinırl1 & Sinırl1 & Sinırli & Sinırli & Sinırs1z & Sinırli & Sinırsiz & Sinırl1 \\
\hline Forum & $\checkmark$ & $x$ & $x$ & $x$ & $\checkmark$ & $\checkmark$ & $x$ & $\checkmark$ & $\checkmark$ \\
\hline Canlı Ders & Eklenti & $\checkmark$ & $\checkmark$ & $\checkmark$ & Eklenti & Eklenti & Eklenti & Eklenti & Eklenti \\
\hline
\end{tabular}

Literatürde yer alan ve ticari olarak kullanılan öğrenme yönetim sistemleri sadece Tablo 1'de verilenler ile sınırlı değildir. Özellikle pandemi dönemi ile uzaktan eğitime talep artışı oluşmuş ve çok sayıda yazılım firması da bu alanda çalışmalarına hız vermiştir.

Öğrenme yönetim sistemlerinden beklenenler 2020 yılına kadar çok kapsamlı değildir. Bu beklentiler doğrultusunda aşağıdaki özelliklere sahip olması yeterliydi.

- Ders içeriklerinin paylaşımı

- Çift taraflı iletişimin sağlanması

- Ölçme ve değerlendirme

- Raporlama

Ancak, 2020 yılında yaygınlaşan pandemi nedeniyle eğitim kurumlarının neredeyse tamamı uzaktan eğitime yönelmiş ve beklentiler bu doğrultuda artmıştır. Geleneksel beklentilere ek olarak aşağıdaki beklentiler de artık kullanıcılar tarafindan ön planda tutulmaktadir.

- Kullanıcı kapasitesi

- Müfredat oluşturma

- Detayli raporlama

- Ders bazli planlama kullanılan yazılımlar ise kullanım yoğunluğuna göre sırasıyla Big Blue Button, Perculus, Microsoft Teams, Zoom, Adobe Connect, Blackboard Collaborate, Google Meet ve Cisco Webex'dir (Durak vd., 2020). Bu yazılımların bazıları açık kaynak kodlu olup kullanımı ücretsizdir. Bazıları ise lisans ücreti ödenerek kullanılabilir.

Öğrenme yönetim sistemi ve canlı ders yazılımları birbirinden bağımsız platformlardır. Ancak, canlı ders yazılımları öğrenme yönetim sistemine entegre edilerek tek bir platform üzerinde kullanılabilir.

Yaygın olarak kullanılan öğrenme yönetim sistemleri ile ilgili karşılaştırma Tablo 1'de verilmiştir. 
Uzaktan eğitim sisteminin bir diğer basamağı olan canlı ders sistemleri bağımsız veya eklenti olarak kullanılabilmektedir. Örneğin, Zoom bağımsız olarak veya eklenti olarak kullanılabilirken, BigBlueButton açık kaynak kodlu sistemlere eklenti olarak dahil edilmektedir. Yaygın olarak kullanılan canlı ders yazılımları Tablo 2'de verilmiştir.

Tablo 2. Canlı ders yazılımlarının karşılaştırması (Herand \& Hatipoğlu, 2014; İzmirli \& Akyüz, 2017; Lavolette vd., 2010; Yıldırım vd., 2011).

\begin{tabular}{|c|c|c|c|c|c|c|c|c|c|c|}
\hline & 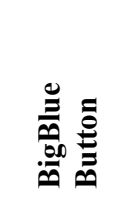 & 氙 & $\stackrel{\Xi}{\stackrel{0}{0}}$ & 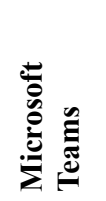 & 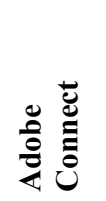 & $\begin{array}{l}\sum_{0}^{ \pm} \\
\sum_{0}^{0} \\
00 \\
0 \\
0 \\
0\end{array}$ & $\begin{array}{l}0 \\
0 \\
0 \\
0 \\
0 \\
0 \\
0\end{array}$ & 氖 & 范 & $\frac{\varrho}{\sqrt{y}}$ \\
\hline Lisans & Ücretsiz & Ücretli & Ücretli & Ücretli & Ücretli & Ücretli & Ücretli & Ücretsiz & Ücretli & Ücretli \\
\hline Kat1lımc1 Sinırı & Değişken & Değişken & $1500+$ & 10000 & 1500 & 10000 & 3000 & Değişken & 3000 & 300 \\
\hline Paylașim & $\checkmark$ & $\checkmark$ & $\checkmark$ & $\checkmark$ & $\checkmark$ & $\checkmark$ & $\checkmark$ & $\checkmark$ & $\checkmark$ & $\checkmark$ \\
\hline Sohbet & $\checkmark$ & $\checkmark$ & $\checkmark$ & $\checkmark$ & $\checkmark$ & $\checkmark$ & $\checkmark$ & $\checkmark$ & $\checkmark$ & $\checkmark$ \\
\hline Kayit & $\checkmark$ & $\checkmark$ & $\checkmark$ & $\checkmark$ & $\checkmark$ & $\checkmark$ & $\checkmark$ & $\checkmark$ & $\checkmark$ & $\checkmark$ \\
\hline Canlı Anket & $\checkmark$ & $\checkmark$ & $\checkmark$ & $x$ & $\checkmark$ & $\checkmark$ & $\checkmark$ & $x$ & $x$ & $x$ \\
\hline $\begin{array}{l}\text { Toplantı ve Sunum } \\
\text { Ayrımı }\end{array}$ & $x$ & $x$ & $\checkmark$ & $x$ & $\checkmark$ & $x$ & $\checkmark$ & $x$ & $x$ & $x$ \\
\hline Entegrasyon & $\checkmark$ & $\checkmark$ & $\checkmark$ & $x$ & $\checkmark$ & $x$ & $\checkmark$ & $\checkmark$ & $\checkmark$ & $\checkmark$ \\
\hline Web Tabanlı & $\checkmark$ & $\checkmark$ & $\checkmark$ & $\checkmark$ & $\checkmark$ & $\checkmark$ & $\checkmark$ & $\checkmark$ & $\checkmark$ & $\checkmark$ \\
\hline Masaüstü & $x$ & $x$ & $\checkmark$ & $\checkmark$ & $\checkmark$ & $\checkmark$ & $\checkmark$ & $x$ & $x$ & $x$ \\
\hline Mobil & $x$ & $x$ & $\checkmark$ & $\checkmark$ & $\checkmark$ & $\checkmark$ & $\checkmark$ & $x$ & $\checkmark$ & $x$ \\
\hline
\end{tabular}

Canlı ders yazılımlarından temel beklenti düşük bant genişliği, sesli ve görüntülü iletişim, ders esnasında sohbet bölümü, kolay entegrasyon ve dersin kayıt altına alınmasıdır. Tablo 2'de verilen canlı ders yazılımları incelendiğinde tüm yazılımların temel beklentileri karşıladığı görülmektedir. Öğrenme yönetim sistemlerindeki talep artışına bağlı yeni sistemlerin geliştirilmesi canlı ders yazılımları için de geçerlidir. Ancak, teknik altyapı olarak canlı ders sistemleri daha spesifik alana hitap etmektedir.

\section{Uzaktan Eğitimde Ölçme ve Değerlendirme Sistemleri}

Ölçme ve değerlendirme, eğitim kurumlarının öğrenci öğrenme durumu ile ilgili geri bildirim almak için kullandığı bir yöntemdir. $\mathrm{Bu}$ yöntem özellikle uzaktan eğitimin son aşaması olarak görülmektedir. Ancak, öğrenme bir süreç gerektirdiği için öğrenme durumu sürekli olarak takip edilmelidir (Baran, 2020). Yani, ölçme ve değerlendirme sadece son aşamaya bırakmayıp süreç içerisinde de yer vermek gerekmektedir. Bu nedenle gerek uzaktan gerekse de örgün eğitimde biçimlendirme (yetiştirme) amaçlı değerlendirme ve öğrenme etkinlikleri sonunda gerçekleştirilen düzey belirleme (değer biçme) amaçlı yapılan değerlendirme kullanılmaktadır (Baran, 2020).

Biçimlendirme amaçlı değerlendirme, ders materyallerinde haftalık, aylık veya bölüm sonunda verilen ve öğrencinin öğrenme süreci içerisindeki öğrenme düzeyini belirlemeye yöneliktir. Düzey belirleme amaçlı değerlendirme ise gözetimli olarak dönem sonu sınavlarını, ödevleri veya projeleri içermektedir (Baran, 2020).

Uzaktan eğitimde, objektif, kolay olması, dijital ortamda kolay kullanılabilmesi ve kişiye özel planlanabilmesi nedeniyle test yöntemi çoğunlukla tercih edilmektedir. Ayrıca, araştırma makalesi ve proje hazırlama gibi sübjektif yöntemlerde kullanılmaktadır (Simonson vd., 2014). Uzaktan eğitimde kullanılan ölçme ve değerlendirme yöntemlerini genel olarak test, sözlü, açık uçlu soru, ödev, kısa cevaplı soru, araştırma makalesi, çevrimiçi tartışma, performans, gösteri, proje, vaka çalışması, eşleştirme, görüşme, portfolyo ve akran değerlendirmesi olarak kategorize edebiliriz.

Uzaktan eğitimde ölçme ve değerlendirmede karşılaşılan en büyük problemlerden birisi kimlik doğrulama problemidir. Yani, sınavın ilgili öğrenci tarafından yapılıp yapılmadığıdır.

Uzaktan eğitimde gerçekleştirilen sınavların güvenilirliği ile ilgili durumlar aşağıda verilmiştir (Bozkurt \& Ucar, 2018; Sindre \& Vegendla, 2015);

- Öğrencinin yerine başkasının sınava girmesi.

- Sinavda başka kişi veya dijital ortamlardan yardım alınması.

- Kopyala/yapıştır çalışmalar yapılması. Referans vermeden kaynak kullanımı.

- Sınav için verilen zaman dilimine uyulmaması.

- Öğrencinin asılsız beyanlar vererek ek süre istemesi veya sınav sonucunu etkilemeye çalışması.

Yukarıda belirtilen faktörler göz önüne alındığında uzaktan eğitimde çevrimiçi gerçekleştirilen sınavlar akademik güvensizlik oluşturmaktadır.

\section{Uzaktan Eğitimde Bulanık Mantık}

Endüstri 4.0 kavramının tüm dünyaya tanıtılması ile başlayan ve pandemi süreci ile hız kazanan dönüşüm, teknolojinin her alanına olduğu gibi eğitim alanına da yansımıştır. Birçok yapay zeka yöntemi eğitim süreçlerinin çeşitli kademelerinde karşımıza çıkmaktadır. Bu bölümde, yapay zeka yöntemlerinin eğitime yansımaları genelinde araştırma yapılmış ve bulanık mantığın uzaktan eğitimde kullanımı detaylı araştırılmıştır.

Yapılan çalışmalar, öğrenci başarısını değerlendirme, öğrenme yönetim sistemi seçimi, performans değerlendirmesi, 
ders içeriği belirleme ve sınav zorluk düzeyi ayarlama üzerine yoğunlaşmaktadır (Çöpgeven \& Fırat, 2019). İncelenen çalışmalarla ilgili özet bilgi Tablo 3 ’te verilmiştir.

Tablo 3. Uzaktan eğitim üzerine yapılan çallş̧maların özeti.

\begin{tabular}{|c|c|c|}
\hline İçerik & Yöntem & Kaynak \\
\hline \multirow{16}{*}{$\begin{array}{l}\text { Öğrenci performansı } \\
\text { değerlendirme }\end{array}$} & Bulanık Mantık & $\begin{array}{l}\text { (Abu Bakar vd., 2020; Annabestani vd., 2019; Azimjonov vd., 2016; Barlybayev } \\
\text { vd., 2016; Cebi \& Karal, 2017; Dashko vd., 2020; Echauz \& Vachtsevanos, } \\
\text { 1995; Ingoley \& Bakal, 2012; Ivanova \& Zlatanov, 2019; Jamsandekar \& } \\
\text { Mudholkar, 2013; Jyothi vd., 2014; Khawar vd., 2020; Ölmez, 2010; Raval \& } \\
\text { Tailor, 2020; Salmi vd., 2014; Ünver, 2020; Wardoyo \& Yuniarti, 2020; Ylldı, } \\
\text { 2014; Yildiz vd., 2013) }\end{array}$ \\
\hline & Yapay Sinir Ağları & (Hassan vd., 2019; Ndukwe vd., 2019; Waheed vd., 2020) \\
\hline & Derin Öğrenme & (Hassan vd., 2019; Sokkhey \& Okazaki, 2019) \\
\hline & Rastgele Orman & $\begin{array}{l}\text { (Abubakar \& Ahmad, 2017; Ghatasheh, 2015; Mahboob vd., 2016; Umer vd., } \\
\text { 2017) }\end{array}$ \\
\hline & Lojistik Regresyon & $\begin{array}{l}\text { (Ghatasheh, 2015; Hassan vd., 2019; Silva vd., 2016; Umer vd., 2017; Waheed } \\
\text { vd., 2020) }\end{array}$ \\
\hline & $\begin{array}{l}\text { Çok Katmanlı } \\
\text { Algılayıcı }\end{array}$ & (Ghatasheh, 2015) \\
\hline & Naive Bayes & $\begin{array}{l}\text { (Ghatasheh, 2015; Kotsiantis vd., 2004; Mahboob vd., 2016; Slater \& Baker, } \\
\text { 2019; Umer vd., 2017) }\end{array}$ \\
\hline & $\begin{array}{l}\text { Destek Vektör } \\
\text { Makineleri }\end{array}$ & (Ghatasheh, 2015; Kotsiantis vd., 2004; Waheed vd., 2020) \\
\hline & C4.5 & (Kotsiantis vd., 2004; Mahboob vd., 2016) \\
\hline & Karar ağaçları & $\begin{array}{l}\text { (Abubakar \& Ahmad, 2017; Ghatasheh, 2015; Hussain vd., 2018; Kotsiantis vd., } \\
\text { 2004; Mahboob vd., 2016) }\end{array}$ \\
\hline & k-Means & (Sisovic vd., 2016) \\
\hline & JRIP & (Hussain vd., 2018) \\
\hline & $\mathrm{J} 48$ & (Hussain vd., 2018) \\
\hline & CART & (Gocheva-Ilieva vd., 2021; Hussain vd., 2018; Kotsiantis vd., 2004) \\
\hline & k-NN & (Abubakar \& Ahmad, 2017; Umer vd., 2017) \\
\hline & Görüntü İşleme & (C. Turan vd., 2018) \\
\hline \multirow{8}{*}{$\begin{array}{l}\text { E-öğrenme sistemi } \\
\text { değerlendirmesi }\end{array}$} & C4.5 & (Sevindik \& Cömert, 2010) \\
\hline & K-means & (Sevindik \& Cömert, 2010) \\
\hline & Apriori & (Cerezo vd., 2017; Sevindik \& Cömert, 2010) \\
\hline & $\begin{array}{l}\text { Destek Vektör } \\
\text { Makineleri }\end{array}$ & (Sevindik \& Cömert, 2010) \\
\hline & k-NN & (Sevindik \& Cömert, 2010) \\
\hline & Naive Bayes & (Hussain vd., 2018; Kotsiantis vd., 2004; Sevindik \& Cömert, 2010) \\
\hline & Dijital İkiz & (David vd., 2018; Patriarcheas \& Xenos, 2009) \\
\hline & Bulanık Mantık & (Ayouni vd., 2021; Doğ, 2012; Hogo, 2010; Naveed vd., 2020) \\
\hline \multirow[b]{2}{*}{$\begin{array}{l}\text { E-öğrenme modeli } \\
\text { oluşturulması }\end{array}$} & Derin Öğrenme & (Antony Rosewelt \& Arokia Renjit, 2020) \\
\hline & Bulanık Mantık & $\begin{array}{l}\text { (Al Duhayyim, 2019, 2019; Antony Rosewelt \& Arokia Renjit, 2020; } \\
\text { Bhattacharya vd., 2017; Dias vd., 2020; Jing vd., 2020; Karac1, 2013; Lee vd., } \\
\text { 2019; Machado vd., 2016; Megahed \& Mohammed, 2020; Ozek vd., 2010) }\end{array}$ \\
\hline \multirow{3}{*}{$\begin{array}{l}\text { E-öğrenmeye devam } \\
\text { edip edilmeyeceğinin } \\
\text { tahmini. }\end{array}$} & Yapay Sinir Ağları & (Lykourentzou vd., 2009; Vandamme vd., 2007) \\
\hline & Rastgele Orman & (Behr vd., 2020; Sokkhey \& Okazaki, 2019) \\
\hline & Doğal Dil İșleme & (Robinson vd., 2016) \\
\hline $\begin{array}{l}\text { Öğrenme yönetim } \\
\text { sistemi seçimi }\end{array}$ & Bulanık Mantık & $\begin{array}{l}\text { (Altun Türker, 2012; Lin vd., 2005; Pariserum Perumal vd., 2019; H. Turan, } \\
\text { 2018) }\end{array}$ \\
\hline Ders içeriği belirleme & Bulanık Mantık & (Gültaş, 2007) \\
\hline $\begin{array}{l}\text { Öğrencilerin derse } \\
\text { katılımını } \\
\text { değerlendirme }\end{array}$ & Bulanık Mantık & (Almohammadi vd., 2017) \\
\hline Materyal öneri sistemi & Bulanık Mantık & (Pandey \& Singh, 2015) \\
\hline $\begin{array}{l}\text { Öğrenme stili } \\
\text { tahmini/önerisi }\end{array}$ & Bulanık Mantık & (Azzi vd., 2020; El Aissaoui vd., 2019; Ozdemir vd., 2016; Ozek vd., 2010) \\
\hline $\begin{array}{l}\text { Öğrenci memnuniyeti } \\
\text { değerlendirme }\end{array}$ & Bulanık Mantık & (Cervero vd., 2020) \\
\hline
\end{tabular}


Uzaktan eğitimde sınıf ortamındaki etkileşim sağlanamadığ için öğrencilerin öğrenme düzeyini ölçmek için gerekli verileri toplamak, analiz etmek ve bunları anlamlandırmak önemlidir. Bu nedenle, literatürde öğrenci performansını değerlendirmeye yönelik yapılan çalışmalarda sadece sınav değerlendirmesi kullanılmamış olup aynı zamanda öğrencinin öğrenme yönetim sistemi üzerindeki davranışları da incelenmiştir. Ayrıca, akademik güvensizliğin önüne geçmek için çeşitli güvenlik önlemleri de ön plana çıkmaktadır.

Gültaş yaptığı tez çalışmasında Matematik ders içeriklerinin belirlenmesi için öğrenci ve eğitimcilere anket uygulamış ve bulanık analitik hiyerarşi proses yöntemi kullanmıştır. Çalışmada öğretim üyelerinin müfredat beklentileri ölçülmüştür. Üniversite sanayi iş birliği ile daha sağlıklı müfredatlar oluşturulabileceği görülmektedir. Sonuç olarak, bulanık AHP metodu müfredat geliştirmek için kullanabilmektedir (Gültaş, 2007).

Hogo, e-öğrenme sistemlerini değerlendirmek için öğrenenleri de kapsayan yapay zeka teknikleri ve istatistiksel araçların hibrit bir modelini kullanmıştır. Öğrencinin profili, değerlendirme sürecinde ve e-öğrenme sürecini iyileştirme önerilerinde çok önemli bir rol oynadığı için öğrencileri profillerine (normal, çalışkan, rahat, kötü ve devamsız) göre kategorilere ayırmaktadır. Çalışma, öğrencileri değerlendirme, öğrenme sisteminin yapısını tasarlama ve kötü öğrencilerin normal hale nasıl dönüştürüleceği sorularına yanıt aramaktadır. Öğrenci profillerini belirlemek için bulanık kümeleme kullanılmıştır (Hogo, 2010).

Ölmez, yüksek lisans tez çalışmasında uzaktan eğitimde sınavların gerçekleştirilmesi için bulanık mantık tabanlı sınav analiz sistemi geliştirmiştir. Sorular zorluk derecesi ve konu seçimine göre hazırlanabilmektedir (Ölmez, 2010).

Üniversitelerin en uygun uzaktan eğitim yönetim sistemini belirlemeyi sağlamak için yapılan çalışmada ise seçim kriterleri ve bulanık mantık kullanılmıştır. Bulanık AHP ve Bulanık TOPSIS yöntemlerini beraber kullanılarak alternatiflerin yakınlık katsayısı belirlenmiştir. En iyi alternatif ise en yüksek değere sahip olandır sonucuna varılmıştır (Altun Türker, 2012).

Sınıflandırma teknikleri, öğrenenlerin sistemle etkileşimlerinden gelen verileri işleyerek öğrenme stillerini otomatik olarak tespit etmek için en çok kullanılan tekniklerdir. $\mathrm{Bu}$ sınıflandırma tekniklerini kullanarak, çeşitli öğrenme stili modelleriyle ve çeşitli yaklaşımlarla önemli sonuçlar elde edilir. $\mathrm{Bu}$ yaklaşımların performansı, kullanılan verilere bağımlıdır. Kullanılan veri sadece bir derse aitse sonuçlar güvenilir olmayabilir. $\mathrm{Bu}$ nedenle, verilerin genel temsil özelliğine sahip olması ve çeşitli derslere karşılık gelen öğrenme davranışlarından toplanması önemlidir.

Jamsandekar ve Mudholkar, bulanık çıkarım tekniği ile öğrenci performanslarını değerlendirmiş ve iki üyelik fonksiyonunun birleşimi olan bir yaklaşım önermişlerdir. Bu amaçla, öğrenci puanları konu bazlı sınıflandırılmıştır. Bulanık çıkarım için MATLAB Fuzzt Tool Box kullanılmıştır (Jamsandekar \& Mudholkar, 2013).

Yıldız vd., çalışmalarında uzaktan öğrenenlerin y1l sonu akademik başarılarını yıl başında tahmin etmek için geliştirilmiş bulanık modelleme kullanmıştır. Bu amaçla, öğrenme yönetim sistemindeki ilk sekiz haftalık veriler, klasik bulanık model, uzman görüşüne dayalı bulanık model, genetik algoritma tabanlı bulanık model ve moodle öğrenme sistemi kullanılmıştır (Yıldız, 2014; Yildiz vd., 2013).

e-ISSN: 2148-2683
Salmi vd., e-öğrenme için bulanık mantık tabanlı değerlendirme sistemi önermiştir. Önerilen sistemde, öğrenciyi değerlendirmek için öğrenci cevaplarında 7 sinıf (UA: unanswered, VP: very poor, P: poor, M: medium, FW: fairy well, G: good, VG: very good) ve çıktı olarak 6 bulanık küme (A: very good, B: good, C: fairly well, D: medium, E: Poor, F: very poor) kullanılmıştır (Salmi vd., 2014).

Pandey ve Singh, öğrencinin gereksinimleri, hedefleri ve ilgisine göre çalışma materyali önermek için multi-agent tabanlı bulanık mantık ve sistemi modellemek için MATLAB kullanmıştır. Modellenen sistemde multi-agent olarak 7 ajan belirlenmiştir. Bunlar; kullanıcı, öğrencinin sistemde kayıtlı veriler, arayüz ajanı, görev ajanı, bilgi ajanı, tavsiye ajanı ve veritabanı ajanı. Arayüz ajanı, kullanıcı ve öğrencinin verileri arasında filtreleme yapmaktadır. Görev ajanı ise öğrenci sorgusuna göre arayüz ajanından gelen verileri analiz etmektedir. Bilgi ajanı, görev ajanından gelen bilgilere göre bilgi tabanından gerekli materyalleri belirler. Tavsiye ajanı, kullanıcı geri bildirimleri ve ulaştığg hedeflere göre yeni öğrenme materyali önermektedir. Veritabanı ajanı, modele ait tüm verileri (ders planları, öğrenme materyalleri, kullanıcı hesapları vb.) tutar (Pandey \& Singh, 2015).

Azimjonov vd., uzaktan eğitimde öğrenci performansını değerlendirmek için bulanık mantık tabanlı yaklaşım önermiştir. Önerilen sistemde 7 faktör (homework, quiz, middle exam, final, watch video, read e-book, attendance) girdi ve öğrenci performansını belirlemek için 8 faktör (failed, weak, weaknormal, normal, normalgood, good, goodexcellent, excellent) çıktı olarak kullanılmıştır (Azimjonov vd., 2016).

Barlybayev vd., öğrenci performansını bulanık mantık ile değerlendirirken ders kazanımlarını (teaorik, uygulama, laboratuar, seminer, kendi kendine öğrenme, arasınav, final vb.) temel almıştır (Barlybayev vd., 2016).

Almohammadi vd., uzaktan eğitimde öğrencilerin derse katılımını ölçmek için Kinect kamera ve tip-2 bulanık mantık kullanmışlardır. Yapılan çalışma ile öğretmenlerin öğretim yöntemlerini öğrencilerin seviyesine uyacak ve öğretim sunumlarını geliştirecek şekilde nasıl değiştirebilecekleri konusunda tavsiyelerde bulunmaktadır (Almohammadi vd., 2017).

Cebi ve Karal, bulanık mantık yaklaşımına dayalı çok kriterli karar verme yöntemlerinden biri olan bulanık analitik hiyerarşi süreci (FAHP) ile üniversite öğrencilerinin geliştirdikleri projeleri bir ders kapsamında değerlendirmek ve en iyi projeyi seçmek amacıyla yapılmıştır. Değerlendirme kriterleri uzman tarafından belirlenmiştir. Değerlendirme yapılırken dilsel değişkenler kullanılmış ve değerlendirme sonrası bu değişkenler bulanık sayılara dönüştürülerek FAHP ile analiz edilmiştir (Cebi \& Karal, 2017).

Annabestani vd., İran'da ilköğretim matematik dersi için öğrenci başarısını değerlendirmede kullanılan 4 kategorinin (Need More Effort (NME), As Expected (AE), Good (G) and Very Good (VG)) öğrencinin öğrenme düzeyini tam olarak ifade etmediği belirterek geri beslemeli bulanık mantık ile yeni bir değerlendirme modeli simule etmişler ve mobil uygulama geliştirmişlerdir. Örneğin, VG'nin sayısal değeri 18-20 arasında kabul edilirse 20 alan öğrenci 18 alana göre VG grubuna daha fazla üyedir. Ayrıca, 17 alan öğrenci G grubundan daha çok VG grubuna üye olabilir. Bu çalışmanın temel amacı bu belirsizliği bulanık mantık ile çözmektir. Model MATLAB ortamında 
hazırlanmıştır. Hazırlanan model 4 değerli bulanık sistem kullanılmış olup her değer İran'da eğitim sürecinin aylarını göstermektedir (7, 9, 10 ve 11.ay). Her bir dönem ayrı bulanık sistem olarak tasarlanmıştır. Ancak, dönemler birbirinin çıktısını girdi olarak kullanan geri besleme kullanmıştır (Annabestani vd., 2019).

Perumal vd., örüntü madenciliği ile öğrencinin sisteme erişim desenlerini kullanarak bulanık kural tabanlı materyal öneri sistemi tasarlamışlardır (Pariserum Perumal vd., 2019).

Ivanova ve Boyan, öğrenci notunu değerlendirirken başarısı iki sınıf arasında sınırda kalan notlar için bulanık mantık tabanlı değerlendirme sistemi kullanmıştır. Örnek olarak, bir testte 60 üzerinden 29 puan alan bir öğrenci başarısız olurken 30 veya 31 puan alan başka bir öğrenci başarılı olacaktır. $\mathrm{Bu}$ problem, borderline test puanlarına sahip öğrencilere daha yüksek veya daha düşük notların atanıp atanmadığını belirlemek için bulanık mantık ve farklı bulanık işlevler kullanılarak ele alınmıştır. Model oluşturulurken 60 soru test ve 1 soru açık uçlu olarak planlanmış ve test güvenilirliği için Cronbach alfa katsayısı hesaplanmıştır. Öğrenci başarısı 5 kategoride değerlendirilmiştir. Bulanık mantık için trapezoidal üyelik fonksiyonu kullanılmıştır (Ivanova \& Zlatanov, 2019).

Ünver, öğrencilerin başarımındaki olumlu/olumsuz farklılıkların psikolojik etkilerini azaltarak performans ve motivasyonun üst seviyede tutulmasını amaçlayan bulanık mantık tabanlı yazılım geliştirmiştir. Matematik dersi esas alınarak yapılan çalışmada üniversite giriş sınavına hazırlanan öğrencilerin ünite sorularına verdikleri doğru cevap sayısı, sınavı alan diğer öğrencilerin ilgili ünitedeki doğru cevap sayıları ve önceki yıllarda alınan ders geçme notları bulanık mantıkla değerlendirilmiş, öğrencilerin her bir ünite için öğrenme oranları belirlenmiştir. Tespit edilen öğrenme oranlarına göre öğrenci düzeyine uygun soru kombinasyonlu sınavlar türetilmiştir. Geliştirilen yazılım ile öğrencilerin moral - motivasyon düzeyini yüksek tutmayı esas alarak sürekli bir gelişim çizgisinin yakalanması hedeflenmiştir (Ünver, 2020, s. 2).

Derin sinir ağları ve bulanık teknikler gibi iki veya daha fazla akıllı sistemin entegrasyonu, hibrit akıllı sistemler olarak adlandırılan sistemlerle sonuçlanır. Bunlar, çeşitli karmaşık gerçek dünya uygulamalarındaki geniş başarılarından dolayı son zamanlarda önemli ölçüde dikkat çekmiştir. İlginç bir örnek, öğrenme sürecinin bir sonraki seviyesinin belirlenebilmesi için ögrenenlerin belirli sorulara verdiği yanıtların dikkate alındığ uyarlanabilir bilgisayar tabanlı öğrenme ortamlarının geliştirilmesidir. Bununla birlikte, bu yöntemler öğrenme sürecinde öğrencinin davranışını ve duygusal ifadelerini yakalayamaz. Bunları yakalamak, öğrenme akışını daha uyarlanabilir hale getirebilir ve öğrenme ortamının, yetenekleri ve etkileşim seviyelerine göre öğrencileri farklı öğrenme yollarına yönlendirmesine izin verebilir.

Megahed ve Ammar, öğrenenlerin sorulara verdiği yanıtların ve duygusal durumlarının entegrasyonunu göz önünde bulundurarak akıllı bir uyarlanabilir e-öğrenme ortamını modellemek için bir yaklaşım önermiştir. Önerilen yaklaşımda evrişimli bir sinir ağı (CNN) ile bulanık bir sistem kullanılmıştır. CNN, yüz ifadesini tespit etmek için ve bulanık sistem, CNN'den çıkarılan yüz ifadesi durumlarına ve öğrenci tarafından çeşitli yanıt faktörlerine dayanarak bir sonraki öğrenme seviyesini belirlemek için kullanılır (Megahed \& Mohammed, 2020).
Abu Bakar vd., bulanık mantık yaklaşımı ile MOOC'da öğrenci performansının tahminini gerçekleştirmiştir. Değerlendirme, çevrimiçi değerlendirme notları ve kendi kendine öğrenme süresi kullanılarak yapılmıştır. Sonuçlar, daha yüksek değerli çevrimiçi değerlendirme notları ve daha yüksek çevrimiçi kendi kendine öğrenme süresinin final sınavında daha yüksek performansa katkıda bulunduğunu göstermiş̧tir (Abu Bakar vd., 2020).

Öğrenci performansını değerlendirmeye yönelik çalışmalarda, anket, öğrenci profili, sınav puanları, sınav değerlendirme, materyal öneri sistemi, ders kazanımları, derse katılım durumu, sınırda kalan notlar ve öğrencilerin psikolojik durumları öncelikli olarak ele alınmıştır.

E-Öğrenim Sistemlerinde, öğrencilerin öğrenme stillerinin otomatik olarak algılanması, eğitmenlerin öğrenmeyi öğrenenlere sunulacak şekilde kişiselleştirmeleri için somut bir yol sağlar. Öğrenme stillerini bulmaya yönelik geleneksel yaklaşım, öğrencilerden anketler ve anketler aracılığıyla kendi tutum ve davranışlarını kendi kendilerine değerlendirmelerini istemeye bağlıdır. $\mathrm{Bu}$ yaklaşım, öğrencilerin kendi tercihleri konusunda kendilerinin farkında olmamaları da dahil olmak üzere çeşitli zayıflıklar sunar. Dahası, öğrencilerin büyük çoğunluğu, kendilerinden ilgili anketi doldurmaları istendiğinde rahatsız olmaktadır. Bunun yanı sıra geleneksel yaklaşım, öğrenme stillerinin sabit olduğunu ve zamanla değişemeyeceğini varsayar.

Özek vd., tarafından tip-2 bulanık mantık temelli yeni bir öğrenci öğrenme stili modeli modülü önerilmiştir. Önerilen modelde, kullanıcının sistemle etkileşiminin geçmişi, zihinsel beceriler, öğrencinin hedefleri, içerik sunumunda yazı, resim veya animasyon tercihi, öğrencinin teknolojik altyapısı, konu hakkındaki öğrencinin bilgisi referans alınmıştır. Bu referanslar doğrultusunda bulanık kurallar belirlenmiştir. Hazırlanan model 20 öğrenciye uygulanarak öğrenciler duyusal, görsel, aktif ve sırasal öğrenme olarak kategorize edilmiştir (Ozek vd., 2010).

Karacı, doktora tez çalışmasında, ses tanıma tanıma teknolojisi kullanan zeki öğretim sistemi geliştirmiştir. Karacı, sistemin öğrenmeyi bireyselleştirdiğini, etkili ve hızlı öğrenmeyi sağladığını belirtmişstir (Karacı, 2013).

Machado vd., yapay zeka tekniklerinin bir öğretim destek aracı olarak kullanımı üzerine odaklanmıştır. Intelligent Tutoring Systems ve Bulanık Mantığı kullanan bu çalışma, elektronik yollarla öğretimin daha verimli olacağını ve grup halinde veya bireysel olarak öğrencilerin gereksinimlerine uyarlanacağını göstermektedir (Machado vd., 2016).

Bireyin yeteneklerine ve kişiliklerine göre en uygun öğrenme stilini belirlemek, hızlı, kolay ve kaliteli öğrenme için çok önemlidir. Her bireyin farklı kişiliği ve yeteneği olduğu düşünüldüğünde, her bireyin en uygun öğrenme stilinin farklı olacağı anlaşılabilir. Yaşam boyu öğrenmenin önemi nedeniyle bireylerin öğrenme stillerini belirlemeye yönelik birçok yöntem ve yaklaşım geliştirilmiştir. Özdemir ve arkadaşları, mühendislik fakültesi personelinin ve öğrencilerin en uygun öğrenme stillerini belirlemek için kural tabanlı bir bulanık mantık çıkarım sistemi geliştirilmiştir. Honey \& Mumford ve McCarthy olmak üzere iki farklı öğrenme stili modeli kullanılmıştır. Honey \& Mumford öğrenme stili mühendislik fakültesi öğrencilerini ve diğerlerini Activist, Reflector, Theorist ve Pragmatist olarak sınıflandırırken; McCarthy öğrenme stili, onları Innovative, Analytic, Common Sense ve Dynamic olarak sınıflandırır (Ozdemir vd., 2016). 
El Aissaoui vd., öğrenme stillerini otomatik olarak tespit etmek için yaklaşım önermiştir. $\mathrm{Bu}$ amaçla, web kullanım madenciliği ile log dosyalarından öğrencilerin öğrenme yapısı tespit edilmiş ve kümeleme algoritmalarını kullanarak, çıkarılan öğrenme yapısını belirli bir öğrenme stili modeline göre sınıflandırılmıştır. Öğrenme stili modeli(LSM) olarak FelderSilverman Modeli ve kümeleme algoritması olarak Fuzzy CMeans kullanılmıştır. Elde edilen sonuçlar, önerilen yaklaşımın geleneksel yaklaşımı geride bıraktığını göstermektedir (El Aissaoui vd., 2019).

Al Duhayyim, yaptığı doktora çalışmasında bulanık mantık ile öğrencinin konudaki her bir kavram için bilgi düzeyini göstermek için renkli bir kavram haritası kullanarak etkili bir uyarlanabilir e-öğrenme sistemini oluşturmayı amaçlamıştır. Önerilen sistemde yönetici, öğrenci ve öğretmen rolleri yer almaktadır. Öğretmen, öğrenci modeli için pre-test ve post-test süreçlerini yürütür. Pre-test ile elde edilen kavram haritasına göre bulanık sistem ile öğrenci öğrenme yapısı oluşturulmaktadır. Kavram haritası her bir öğrenci için öğrenme düzeylerini göstermektedir (Al Duhayyim, 2019).

Lee vd., e-öğrenme sistemlerini iyileştirmeye yönelik öneriler sağlayarak değerlendirme ve analiz için performans matrisi ve bulanık değerlendirme tabanlı bir model oluşturmuştur. Performans matrisi öğrenci arayüzü, öğrenme topluluğu, sistem içeriği ve kişiselleştirme başlıklarında 13 adet bilgi içermektedir. $\mathrm{Bu}$ bilgileri içeren anket bilgisayar destekli dil öğrenen ögrencilere uygulanmış ve elde edilen sonuçlar bulanık mantık ile değerlendirilmiştir. Sonuç olarak, e-öğrenme sisteminin kalitesini iyileştirmiş, kullanıcıların öğrenme etkinliğini, memnuniyetini ve katılımını artırmış ve sürdürülebilirlik sağlamıştır (Lee vd., 2019).

Azzi vd., e-öğrenim sisteminde öğrencinin öğrenme stilini tanımlayabilen sınıflandırıcı üzerinde çalışmıştır. Sınıflandırıcı olarak fuzzy c-means, öğrenci verilerini elde etmek için web kullanım madenciliği ve Felder-Silverman Öğrenme Stili Modeli kullanılmıştır (Azzi vd., 2020).

Naveed vd., web tabanlı e-öğrenim sisteminin farklı boyutlarından çeşitli faktörleri incelemek için grup karar verme (GDM) ve Fuzzy AHP (FAHP) ile analitik hiyerarşi sürecini (AHP) kullanmıştır. Web tabanlı E-Öğrenme sistemiyle ilişkili beş farklı boyut (öğrenci, eğitimci, tasarım ve içerik, sistem ve teknoloji, kurumsal yönetim) ve 25 faktör, literatür taraması yoluyla ortaya çıkarılmış ve analiz edilmiştir (Naveed vd., 2020).

Cervero vd., çevrimiçi öğretme-öğrenme sürecini etkileyen ana değişkenleri bulmak için öğrenci memnuniyetini analiz etmiştir. Bu amaçla, SPSS ve Matlab yazılımlarını kullanarak tanımlayıcı analizler, sınıflandırma ağaçları ve bulanık çıkarım sistemleri ile 1084 üniversite öğrencisine uygulanan anket kullanılmıştır. İlk olarak, çalışma örnekleminin ankete dayalı olarak nitel ve nicel analizi yapılmıştır. Ardından, sanal bir kampüste eğitim kalitesini değerlendirmek için en iyi modeli belirlemek için karar ağaçları kullanılmıştır. $\mathrm{Bu}$ süreçteki belirsizlikleri gidermek için bulanık çıkarım kullanılmıştır (Cervero vd., 2020).

Öğrenim yönetim sisteminin kalitesinin değerlendirilmesi, öğrenenlerin sonuçlarını iyileştirmek ve öğretim stratejisini geliştirmek için önemlidir. Pek çok ÖYS ortaya çıkmaktadır ve bu nedenle kurumların uygun ÖYS'yi seçmelerine yardımcı olmak, özellikle belirsizliklerin ve öznelliklerin dikkate alındığı bulanık ortamda çok önemli hale gelmektedir.
Ayouni vd., öğrenme yönetim sistemlerini değerlendirmek için bulanık Vikor yöntemini kullanmıştır. Elde edilen sonuçlar, karar vericiler için en önemli kriterin eşit derecede anlaşılabilirlik ve zaman davranışı olduğunu göstermektedir. Ek olarak, açık kaynak Moodle, yüksek öğretim kurumlarının standartlarını karşılamak için uygun LMS olarak belirlenmiştir. (Ayouni vd., 2021)

Öğrenme stili belirleme ve öğrenme modeli oluşturma üzerine yapılan çalışmalarda, öğrencinin sistem üzerindeki desenleri, zihinsel becerileri, mevcut öğrenme modellerinin uygulaması ve kavram haritası ön plana çıkmaktadır.

\section{Sonuçlar}

Posta yoluyla başlayan uzaktan eğitim teknolojinin gelişmesine paralel olarak günümüzde zaman ve mekan bağımsız olarak senkron veya asenkron şekilde gerçekleştirilmektedir. Kendine özgü pozitif yönleri olsa da öğrenci-eğitimci etkileşiminin düşük olması, suiistimale açık olması veya objektif bir değerlendirme yapılamaması en önemli olumsuz yönleridir. $\mathrm{Bu}$ olumsuzlukları bertaraf etmek için birçok yöntem tercih edilmektedir. Bunlar;

- Eğitim süresinin \%70 nin uzaktan, \% 30 unun yüz yüze yapılmas1. Pandemi öncesi uzaktan eğitim gerçekleştiren yüksek öğretim kurumları bu şekilde uygulama gerçekleştirebiliyordu. Ancak, pandemi ile birlikte uzaktan eğitim uygulaması sadece bu sisteme kayıtlı olan öğrencilere değil genele yayıldı ğı için bu her zaman uygulanabilecek bir yöntem değildir.

- Derslerin hem senkron hem de asenkron olarak yapilmas1.

- Öğrencinin uzaktan eğitim sisteminde kaldığı süre boyunca hareket desenlerinin çıkartılması.

- Senkron eğitimde öğrencinin sesli ve görüntülü olarak takibi.

- Öğrenci performansını değerlendirmek için farklı objektif yöntemlere başvurulması.

Yukarıda verilen maddeler uzaktan eğitimi bir nebze daha etkileşimli ve objektif eğitime doğru yönlendirmektedir. Burada vurgulanması gereken önemli bir nokta ise eğitim ve öğretim kavramlarının birbirine karıştırılmasıdır. Bireyin davranışlarında kendi yaşantıları yoluyla, kasıtlı olarak istendik yönde davranış değişikliği meydana getirme sürecidir. Yani, sadece okulda olan süreç olmayıp doğumdan başlayıp yaşam boyu devam eder. Öğretim ise eğitimin okullarda gerçekleştirildiği kısımdır. Bu kapsamda, uzaktan eğitim ifadesinin mevcut kullanım şekliyle içi boş kalmaktadır. Bu nedenle, her ne kadar uzaktan eğitim olarak ifade etsek de bu amaçla kullanılan platformlar öğrenme yönetim sistemi olarak ifade edilmektedir.

Gerek açık kaynak kodlu gerekse de ücretli olarak hizmet veren birçok öğrenme yönetim sistemi mevcuttur. Kullanılacak yazılımın belirlenmesinde canlı ders süresi, katılımcı sınırı, kayıt özelliği gibi öncelikli gereksinimlerin göz önüne alınması gerekmektedir. Bu gereksinimlere ek olarak bütçe, teknik altyapı ve kullanım kolaylığı da göz önüne alınmalıdır. Yaygın olarak kullanılan öğrenme yönetim sistemleri incelendiğinde asenkron süreç için hepsi benzer özelliklere sahip olup temel ihtiyaçları karşılamaktadır. Bunlarda en yaygın olarak kullanılan açık kaynak kodlu Moodle sistemidir. Birçok kurum bu sistemi kendine göre revize ederek kullanmaktadır. Açık kaynak kodlu 
sistemlerin ücretsiz olmasına ek olarak diğer avantajı uzman teknik personel yardımıyla isteğe göre uyarlanabilmesidir.

Günümüzde kurumlar tümleşik öğrenme yönetim sistemlerini kullanmaktadır. Bu sistemler, senkron ve asenkron eğitime olanak tanıdığı gibi e-sınav yapılmasını da sağlamaktadır. Senkron eğitim için zoom, bigbluebutton, webex gibi kullanılan çok çeşitli uygulamalar mevcuttur. Bu uygulamaları birbirinden ayırt eden en büyük özellikler kullanıcı kapasitesi, kesintisiz hizmet için altyapı ve lisans durumudur.

Mevcut öğrenme yönetim sistemleri ölçme ve değerlendirme yöntemleri için teknik altyapıya sahiptir. Sınavın güvenilirliği ile ilgili önemli tereddütler bulunmaktadır. Bunlardan en önemlisi de öğrencinin farklı yöntemlerle kopyaya yönelmesidir. Bu nedenle, uzaktan eğitimde çevrimiçi gerçekleştirilen sınavlar akademik güvensizlik oluşturmaktadır. Bu güvensizliği ortadan kaldırmak için kimlik doğrulama ve çeşitli güvenlik yöntemleri (IP kısıtlaması, ayna kullanımı, kamera ile anlık görüntü alımı, tarayıcı üzerinde sınırlandırmalar, zaman sınırlaması, hareketsiz kalma süresi takibi) kullanılmaktadır. Kimlik doğrulama için biyometrik, bilgi veya nesne tabanlı yöntemler kullanılmaktadır. Ancak, bu yöntemler hem ekonomik hem de kullanım açısından maliyetli yöntemlerdir. Ayrıca, yukarıda belirtilen güvenilirlik durumları için çözüm sağlamayacaktır.

Gerek ölçme ve değerlendirme için gerekse de öğrenme sürecinin iyileştirilmesine yönelik literatürde yapılmış çeşitli çalışmalar mevcuttur. Yapay zeka kapsamında yapılan çalışmalar önceki bölümlerde detaylı olarak açıklanmıştır. Bu çalışmalar yoğunluklarına göre ele alınacak olursa, öğrenci performansı değerlendirme, öğrenme yönetim sistemi değerlendirme ve öğrenme modeli oluşturma çoğunlukla çalışılan konular olmuştur.

Öğrenci performansını değerlendirmeye yönelik çalışmalarda, anket, öğrenci profili, sınav puanları, sınav değerlendirme, materyal öneri sistemi, ders kazanımları, derse katılım durumu, sınırda kalan notlar ve öğrencilerin psikolojik durumları öncelikli olarak ele alınmıştır.

Öğrenme stili belirleme ve öğrenme modeli oluşturma üzerine yapılan çalışmalarda, öğrencinin sistem üzerindeki desenleri, zihinsel becerileri, mevcut öğrenme modellerinin uygulaması ve kavram haritası ön plana çıkmaktadır.

\section{Kaynakça}

Abu Bakar, N., Rosbi, S., \& Bakar, A. A. (2020). Robust Estimation of Student Performance in Massive Open Online Course using Fuzzy Logic Approach. International Journal of Engineering Trends and Technology, 143-152.

Abubakar, Y., \& Ahmad, N. B. H. (2017). Prediction of Students' Performance in E-Learning Environment Using Random Forest. International Journal of Innovative Computing, 7(2), Article 2.

Al Duhayyim, M. (2019). Concept-based and fuzzy adaptive elearning (CaFAE) [Doctoral, University of Sussex]. http://sro.sussex.ac.uk/id/eprint/86221/

Almohammadi, K., Hagras, H., Yao, B., Alzahrani, A., Alghazzawi, D., \& Aldabbagh, G. (2017). A type-2 fuzzy logic recommendation system for adaptive teaching. Soft Computing, 21(4), 965-979.

Altun Türker, Y. (2012). Uzaktan eğitim öğretim yönetim sisteminin bulanık çok kriterli karar verme yöntemleri ile seçimi [Master's Thesis]. Kocaeli Universitesi, Fen Bilimleri Enstitusu.

Annabestani, M., Rowhanimanesh, A., Mizani, A., \& Rezaei, A. (2019). Descriptive evaluation of students using fuzzy approximate reasoning. arXiv:1905.02549 [cs].

e-ISSN: 2148-2683
Antony Rosewelt, L., \& Arokia Renjit, J. (2020). A content recommendation system for effective e-learning using embedded feature selection and fuzzy DT based CNN. Journal of Intelligent \& Fuzzy Systems, 39(1), 795-808.

Aydoğdu Karaaslan, I. (2019). Açık Kaynak Kodlu ve Ticari Web Tabanlı Uzaktan Eğitim Yazılımlarının Karşılaştırılması. Journal of International Social Research, 12(62), 979-990.

Ayouni, S., Menzli, L. J., Hajjej, F., Madeh, M., \& Al-Otaibi, S. (2021). Fuzzy Vikor Application for Learning Management Systems Evaluation in Higher Education. Http://Services.IgiGlobal.Com/Resolvedoi/Resolve.Aspx?Doi=10.4018/IJICTE.20 21040102, 17(2), 17-35.

Azimjonov, J., Selvi, İ. H., \& Özbek, U. (2016). Evaluatıon of distance learnıng students performance usıng fuzzy logıc. Yönetim Bilişim Sistemleri Dergisi, 2(2), 87-97.

Azzi, I., Jeghal, A., Radouane, A., Yahyaouy, A., \& Tairi, H. (2020). A robust classification to predict learning styles in adaptive Elearning systems. Education and Information Technologies, 25(1), 437-448.

Baran, H. (2020). Açık ve uzaktan eğitimde ölçme ve değerlendirme. Açıöğretim Uygulamaları ve Araştırmaları Dergisi, 6(1), 28-40.

Barlybayev, A., Sharipbay, A., Ulyukova, G., Sabyrov, T., \& Kuzenbayev, B. (2016). Student's Performance Evaluation by Fuzzy Logic. Procedia Computer Science, 102, 98-105.

Behr, A., Giese, M., K, H. D. T., \& Theune, K. (2020). Early Prediction of University Dropouts - A Random Forest Approach. Jahrbücher Für Nationalökonomie Und Statistik, 240(6), 743789.

Bhattacharya, S., Chowdhury, S., \& Roy, S. (2017). Enhancing Quality of Learning Experience Through Intelligent Agent in ELearning. International Journal of Uncertainty, Fuzziness and Knowledge-Based Systems, 25(01), 31-52.

Bozkurt, A., \& Ucar, H. (2018). E-Öğrenme ve E-Sinavlar: Çevrimiçi Ölçme Değerlendirme Süreçlerinde Kimlik Doğrulama Yöntemlerine İlişkin Öğrenen Görüsllerinin Incelenmesi.

Can, Ş. (2008). Fen eğitiminde web tabanlı eğitim. Celal. Bayar Üniversitesi.

Cebi, A., \& Karal, H. (2017). An application of fuzzy analytic hierarchy process (FAHP) for evaluating students project. Educational Research and Reviews, 12(3), 120-132.

Cerezo, R., Esteban, M., Sánchez-Santillán, M., \& Núñez, J. C. (2017). Procrastinating Behavior in Computer-Based Learning Environments to Predict Performance: A Case Study in Moodle. Frontiers in Psychology, 8, 1403.

Cervero, A., Castro-Lopez, A., Álvarez-Blanco, L., Esteban, M., \& Bernardo, A. (2020). Evaluation of educational quality performance on virtual campuses using fuzzy inference systems. PLOS ONE, 15(5), e0232802.

Cisco Webex. (t.y.). Geliş tarihi 27 Şubat 2021, gönderen https://www.webex.com/

Çöpgeven, S., \& Fırat, M. (2019). Uzaktan eğitimde algoritmalar: 2007-2019 sistematik alanyazin taramasi.

Dashko, Y., Vitchenko, O., \& Kadomtsev, M. (2020). Soft models of competence assessment in professional education. E3S Web of Conferences, 210, 18011.

David, J., Lobov, A., \& Lanz, M. (2018). Leveraging Digital Twins for Assisted Learning of Flexible Manufacturing Systems. 2018 IEEE 16th International Conference on Industrial Informatics (INDIN), 529-535.

Dias, S. B., Dolianiti, F. S., Hadjileontiadou, S. J., Diniz, J. A., \& Hadjileontiadis, L. J. (2020). On modeling the quality of concept mapping toward more intelligent online learning feedback: A fuzzy logic-based approach. Universal Access in the Information Society, 19(3), 485-498.

Doğ, M. F. (2012). Uzaktan Eğitim Sistemlerinde Kullanılabilirlik Ölçütleri [Yüksek Lisans Tezi]. Bahçeşehir Üniversitesi. 
Durak, G., Çankaya, S., \& İzmirli, S. (2020). COVID-19 pandemi döneminde Türkiye'deki üniversitelerin uzaktan eğitim sistemlerinin incelenmesi. Necatibey Eğitim Fakültesi Elektronik Fen ve Matematik Ë̆itimi Dergisi, 14(1), 787-809.

Echauz, J. R., \& Vachtsevanos, G. J. (1995). Fuzzy Grading System. IEEE Transactions on Education, 38(2), 158-165.

El Aissaoui, O., El Alami El Madani, Y., Oughdir, L., \& El Allioui, Y. (2019). A fuzzy classification approach for learning style prediction based on web mining technique in e-learning environments. Education and Information Technologies, 24(3), 1943-1959.

Ghatasheh, N. (2015). Knowledge Level Assessment in e-Learning Systems Using Machine Learning and User Activity Analysis. International Journal of Advanced Computer Science and Applications, 6(4).

Gocheva-Ilieva, S., Kulina, H., \& Ivanov, A. (2021). Assessment of Students' Achievements and Competencies in Mathematics Using CART and CART Ensembles and Bagging with Combined Model Improvement by MARS. Mathematics, 9(1), 62.

GoToMeeting. (t.y.). Geliş tarihi 27 Şubat 2021, gönderen https://www.gotomeeting.com/en-tr

Gültaş, İ. (2007). Endüstri Mühendisliği Eğitiminde Matematik Ders Içeriklerinin Belirlenmesine Bulanık Ahp Yöntemi İle Çözüm Önerisi [Thesis, Fen Bilimleri Enstitüsü]. https://polen.itu.edu.tr/handle/11527/5845

Hassan, S.-U., Waheed, H., Aljohani, N. R., Ali, M., Ventura, S., \& Herrera, F. (2019). Virtual learning environment to predict withdrawal by leveraging deep learning. International Journal of Intelligent Systems, 34(8), 1935-1952.

Herand, D., \& Hatipoğlu, Z. A. (2014). Uzaktan Eğitim ve Uzaktan Eğitim Platformları'nın Karşılaştırılması. Çukurova Üniversitesi Íktisadi ve Ídari Bilimler Fakültesi Dergisi, 18(1).

Hogo, M. A. (2010). Evaluation of e-learning systems based on fuzzy clustering models and statistical tools. Expert Systems with Applications, 37(10), 6891-6903.

Hussain, M., Zhu, W., Zhang, W., \& Abidi, S. M. R. (2018, Ekim 2). Student Engagement Predictions in an e-Learning System and Their Impact on Student Course Assessment Scores [Research Article]. Computational Intelligence and Neuroscience; Hindawi.

Ingoley, S. N., \& Bakal, J. W. (2012). Students' performance evaluation using fuzzy logic. 2012 Nirma University International Conference on Engineering (NUiCONE), 1-6.

Işık, A. H., Karacı, A., Özkaraca, O., \& Biroğul, S. (2010). Web tabanlı eş zamanlı (senkron) uzaktan eğitim sistemlerinin karşılaştırmalı analizi. Akademik Bilişim, 10-12.

İşman, A. (1998). Uzaktan eğitim: Genel tanımı, Türkiye'deki gelişimi, proje değerlendirmeleri. Değişim Yayınları.

Ivanova, V., \& Zlatanov, B. (2019). Implementation of Fuzzy Functions Aimed at Fairer Grading of Students' Tests. Education Sciences, 9(3), 214.

İzmirli, S., \& Akyüz, H. İ. (2017). Eş Zamanlı Sanal Sınıf Yazılımlarının İncelenmesi. Eğitimde Kuram ve Uygulama, 13(4), 788-810.

Jamsandekar, S. S., \& Mudholkar, R. R. (2013). Performance Evaluation by Fuzzy Inference Technique. /paper/PerformanceEvaluation-by-Fuzzy-Inference-Technique-JamsandekarMudholkar/3fdf3fe33aaec8ce33873f6760c37af1c33dd3dc

Jing, X., Yan, Z., Shen, Y., Pedrycz, W., \& Yang, J. (2020). A GroupBased Distance Learning Method for Semisupervised Fuzzy Clustering. IEEE Transactions on Cybernetics, 1-14.

Jyothi, G., Parvathi, M. C., Srinivas, M. P., \& Althaf, M. S. (2014). Fuzzy Expert Model for Evaluation of Faculty Performance in Technical Educational Institutions. 4(5), 10.

Karacı, A. (2013). Ses Sentezleme Ve Tanıma Teknolojilerini Kullanarak Türkçenin Ana Dil Olarak Öğretimi Iç̧in Zeki Ögretim Sistemi Geliştirilmesi [Doktora Tezi]. Gazi Üniversitesi.
Karadimas, N. V. (2018). Comparing Learning Management Systems from Popularity Point of View. 2018 5th International Conference on Mathematics and Computers in Sciences and Industry (MCSI), 141-146.

Khawar, K., Munawar, S., \& Naveed, N. (2020). Fuzzy Logic-based Expert System for Assessing Programming Course Performance of E-Learning Students. Journal of Information Communication Technologies and Robotic Applications, 54-64.

Kotsiantis, S., Pierrakeas, C., \& Pintelas, P. (2004). Predicting Students' Performance in Distance Learning Using Machine Learning Techniques. Applied Artificial Intelligence, 18(5), 411426.

Küçükönder, N., \& İbrahim, K. I. R. (2016). Uzaktan Eğitim Uygulamalarında Açık Kaynak Kodlu Öğrenme Yönetim Sistemlerinin Yeniden Yapılandırılmasının İncelenmesi. Kahramanmaraş Sütçü İmam Üniversitesi Sosyal Bilimler Dergisi, 13(1).

Lavolette, E., Venable, M. A., Gose, E., \& Huang, E. (2010). Comparing synchronous virtual classrooms: Student, instructor and course designer perspectives. TechTrends, 54(5), 54-61.

Lee, T.-S., Wang, C.-H., \& Yu, C.-M. (2019). Fuzzy Evaluation Model for Enhancing E-Learning Systems. Mathematics, 7(10), 918.

Lin, C.-B., Young, S. S.-C., Chan, T.-W., \& Chen, Y.-H. (2005). Teacher-oriented adaptive Web-based environment for supporting practical teaching models: A case study of "school for all”. Computers \& Education, 44(2), 155-172.

Lykourentzou, I., Giannoukos, I., Mpardis, G., Nikolopoulos, V., \& Loumos, V. (2009). Early and dynamic student achievement prediction in e-learning courses using neural networks. Journal of the American Society for Information Science and Technology, 60(2), 372-380.

Machado, M. A. S., Moreira, T. D. R. G., Gomes, L. F. A. M., Caldeira, A. M., \& Santos, D. J. (2016). A Fuzzy Logic Application in Virtual Education. Procedia Computer Science, 91, 19-26.

Mahboob, T., Irfan, S., \& Karamat, A. (2016). A machine learning approach for student assessment in E-learning using Quinlan's C4.5, Naive Bayes and Random Forest algorithms. 2016 19th International Multi-Topic Conference (INMIC), 1-8.

Megahed, M., \& Mohammed, A. (2020). Modeling adaptive ELearning environment using facial expressions and fuzzy logic. Expert Systems with Applications, 157, 113460.

Microsoft Teams. (t.y.). Geliş tarihi 27 Şubat 2021, gönderen https://www.microsoft.com/tr-tr/microsoft-teams/group-chatsoftware

Moodle-Open-source learning platform | Moodle.org. (t.y.). Geliş tarihi 27 Şubat 2021, gönderen https://moodle.org/?lang=tr

Naveed, Q. N., Qureshi, M. R. N., Tairan, N., Mohammad, A., Shaikh, A., Alsayed, A. O., Shah, A., \& Alotaibi, F. M. (2020). Evaluating critical success factors in implementing E-learning system using multi-criteria decision-making. PLOS ONE, 15(5), e0231465.

Ndukwe, I. G., Daniel, B. K., \& Amadi, C. E. (2019). A Machine Learning Grading System Using Chatbots. Içinde S. Isotani, E. Millán, A. Ogan, P. Hastings, B. McLaren, \& R. Luckin (Ed.), Artificial Intelligence in Education (ss. 365-368). Springer International Publishing.

Ozdemir, A., Alaybeyoglu, A., Mulayim, N., \& Balbal, K. F. (2016). Performance evaluation of learning styles based on fuzzy logic inference system. Computer Applications in Engineering Education, 24(6), 853-865.

Ozek, M., Akpolat, Z., \& Orhan, A. (2010). Web tabanli akilli ögretim sistemlerinde tip-2 bulanik mantik kullanarak öğrenci ög̀renme stili modelleme. Firat Üniversitesi Mühendislik Bilimleri Dergisi, 22, 37-44.

Ölmez, Ç. (2010). Uzaktan Eğitim Sistemlerindeki Soru Bankalarının Bulanık Mantık Yöntemi Ille Analizi [Yüksek Lisans Tezi, Afyon Kocatepe http://acikerisim.aku.edu.tr/xmlui/handle/11630/6283 Üniversitesi]. 
Özkaraca, O. (2005). Internet tabanlı güç elektroniği eğitimi $[\mathrm{PhD}$ Thesis]. Yüksek Lisans Tezi, Gazi Üniversitesi Fen Bilimleri Enstitüsü, Ankara, 1-125.

Pandey, H., \& Singh, V. K. (2015). A Fuzzy Logic based Recommender System for E-Learning System with Multi-Agent Framework. International Journal of Computer Applications, 122(17), 18-21.

Pariserum Perumal, S., Sannasi, G., \& Arputharaj, K. (2019). An intelligent fuzzy rule-based e-learning recommendation system for dynamic user interests. The Journal of Supercomputing, 75(8), 5145-5160.

Patriarcheas, K., \& Xenos, M. (2009). Modelling of distance education forum: Formal languages as interpretation methodology of messages in asynchronous text-based discussion. Computers \& Education, 52(2), 438-448.

Raval, S., \& Tailor, B. (2020). Mathematical Modelling of Students' Academic Performance Evaluation Using Fuzzy Logic. International Journal of Statistics and Reliability Engineering, 7(1), 149-159.

Robinson, C., Yeomans, M., Reich, J., Hulleman, C., \& Gehlbach, H. (2016). Forecasting student achievement in MOOCs with natural language processing. Proceedings of the Sixth International Conference on Learning Analytics \& Knowledge, 383-387.

Salmi, K., Magrez, H., \& Ziyyat, A. (2014). A fuzzy expert system in evaluation for E-learning. 2014 Third IEEE International Colloquium in Information Science and Technology (CIST), 225229.

Saraç, M. A. Y. (2020). Preparing a national roadmap for online higher education. University World News. https://www.universityworldnews.com/post.php?story=2020041 5120209980

Schullo, S., Hilbelink, A., Venable, M., \& Barron, A. E. (2007). Selecting a virtual classroom system: Elluminate live vs. Macromedia breeze (adobe acrobat connect professional). MERLOT Journal of Online Learning and Teaching, 3(4), 331345.

Sevindik, T., \& Cömert, Z. (2010). Using algorithms for evaluation in web based distance education. Procedia-Social and Behavioral Sciences, 9, 1777-1780.

Silva, J. C. S., Ramos, J. L. C., Rodrigues, R. L., Gomes, A. S., Souza, F. D. F. D., \& Maciel, A. M. A. (2016). An EDM Approach to the Analysis of Students' Engagement in Online Courses from Constructs of the Transactional Distance. 2016 IEEE 16th International Conference on Advanced Learning Technologies (ICALT), 230-231.

Simonson, M., Smaldino, S., \& Zvacek, S. M. (Ed.). (2014). Teaching and Learning at a Distance: Foundations of Distance Education, 3rd Edition (Revised ed. edition). Information Age Publishing.

Sindre, G., \& Vegendla, A. (2015). E-exams versus paper exams: A comparative analysis of cheating-related security threats and countermeasures. NISK Journal, 34-45.
Sisovic, S., Matetic, M., \& Bakaric, M. B. (2016). Clustering of imbalanced moodle data for early alert of student failure. 2016 IEEE 14th International Symposium on Applied Machine Intelligence and Informatics (SAMI), 165-170.

Slater, S., \& Baker, R. (2019). Forecasting future student mastery. Distance Education, 40(3), 380-394.

Sokkhey, P., \& Okazaki, T. (2019). Comparative Study of Prediction Models on High School Student Performance in Mathematics. 2019 34th International Technical Conference on Circuits/Systems, Computers and Communications (ITC-CSCC), $1-4$.

Turan, C., Reis, Z. A., \& Gülseçen, S. (2018). Bakış Takibi ile EÖğrenme Materyalinde Konu Odă̆ ve Ö̆grenci Bakıs Reflekslerinin İlgisini Değerlendirme.

Turan, H. (2018). Assessment factors affecting e-learning using fuzzy analytic hierarchy process and SWARA. The International Journal of Engineering Education, 34(3), 915-923.

Ulutaş, F., \& Ubuz, B. (2008). Matematik Eğitiminde Araştırmalar ve Eğilimler: 2000 ile 2006 Yılları Arası. Ilkogretim Online, 7(3).

Umer, R., Susnjak, T., Mathrani, A., \& Suriadi, S. (2017). On predicting academic performance with process mining in learning analytics. Journal of Research in Innovative Teaching \& Learning, 10(2), 160-176.

Ünver, H. M. (2020). Design of a Fuzzy Logic Based Custom Exam Production System for High Performance. Uluslararast Muhendislik Arastirma ve Gelistirme Dergisi, 745-752.

Vandamme, J.-P., Meskens, N., \& Superby, J.-F. (2007). Predicting academic performance by data mining methods. Education Economics, 15(4), 405.

Waheed, H., Hassan, S.-U., Aljohani, N. R., Hardman, J., Alelyani, S., \& Nawaz, R. (2020). Predicting academic performance of students from VLE big data using deep learning models. Computers in Human Behavior, 104, 106189.

Wardoyo, R., \& Yuniarti, W. D. (2020). Analysis of Fuzzy Logic Modification for Student Assessment in e-Learning. IJID (International Journal on Informatics for Development), 9(1), 2936.

Yıldırım, D., Tüzün, H., Çınar, M., Akıncı, A., Kalaycı, E., \& Bilgiç, H. G. (2011). Uzaktan eğitimde kullanılan eşzamanlı sanal sınıf araçlarının karşılaştırılması. Akademik Bilişim, 451-456.

Yıldız, O. (2014). Makine öğrenmesi ile uzaktan ĕgitim öğrencilerinin performanslarının değerlendirilmesi-Tez Arşivi [Doktora Tezi, İstanbul Üniversitesi]. https://tezarsivi.com/makine-ogrenmesiile-uzaktan-egitim-ogrencilerinin-performanslarinindegerlendirilmesi

Yildiz, O., Bal, A., \& Gulsecen, S. (2013). Improved fuzzy modelling to predict the academic performance of distance education students. The International Review of Research in Open and Distributed Learning, 14(5).

Zoom. (t.y.). Geliş tarihi 27 Şubat 2021, gönderen https://zoom.us/ 